\title{
Level Of Passing Skills In Soccer Learning
}

\author{
Rohmatullah $^{1)}$, Rina Marlina ${ }^{2)}$, Ruslan Abdul Gani ${ }^{3)}$ \\ ${ }^{1,3}$ Program Studi Pendidikan Jasmani Kesehatan dan Rekreasi \\ ${ }^{2}$ Program Studi Pendidikan Matematika \\ Fakultas Keguruan dan Ilmu Pendidikan \\ ${ }^{1,2,3}$ Universitas Singaperbangsa Karawang, Jawa Barat Indonesia \\ Email: 1rohmatullah170197@gmail.com, 2Rinamarlina89@gmail.com, \\ 33ruslan.abdulgani@staff.unsika.ac.id
}

\begin{abstract}
This study aims to learn the skills passed by learning ball class $X$ students in Jasinga 1 High School. Using quantitative research with survey methods. The sampling technique used was purposive sampling with a total sample of 30 male students. The instrument used was the graduation skills test used by Jaelani (2014). Data analysis techniques using quantitative descriptive analysis techniques as outlined in the form of percentages. The results of research on skills that pass of soccer learning in class X of SMAN 1 Jasinga are in the category of "skills" with a percentage of $53.3 \%$, the category of "moderately skilled" with a percentage of $26.7 \%$, the category of "very talented" with a percentage of 20,0\%. While the category of "less successful" and "very less" with a percentage of $0.0 \%$. The conclusion of this study is the level of passing skills in learning soccer class X Jasinga SMAN 1 depends on the category of expertise.
\end{abstract}

Keywords: Skill, Passing, Soccer.

\section{Tingkat Keterampilan Passing Pada Pembelajaran Sepak Bola ABSTRAK}

Penelitian ini bertujuan untuk menilai keterampilan passing pada pembelajaran sepak bola siswa kelas X di SMAN 1 Jasinga dengan menggunakan metode survey jenis kuantitatif. Penarikan sampel dilakukan dengan menggunakan purposive sampling dengan jumlah sampling sebanyak 30 siswa putra. Instrumen yang digunakan adalah tes keterampilan passing yang digunakan oleh Jaelani (2014). Teknik analisis data menggunakan teknik analisis deskriptif kuantitatif. Keterampilan passing pada pembelajaran sepak bola kelas X SMAN 1 Jasinga berada dalam kategori "baik" dengan persentase 53.3, kategori "cukup baik" dengan persentase 26.7, kategori "sangat baik" dengan persentase 20.0. Selanjutnya, kategori "kurang baik" dan "sangat kurang" dengan persentase 0.0. Kesimpulan dari penelitian ini adalah tingkat keterampilan passing pada pembelajaran sepak bola kelas X SMAN 1 Jasinga berada pada kategori baik.

Kata Kunci; Keterampilan, Passing, Sepak Bola

Info Artikel

Dikirim

Diterima

: 30 Juli 2020

: 14 September 2020

Dipublikasikan : 12 November 2020
(C) 2020 IKIP BUDI UTOMO MALANG

P-ISSN 2613-9421

E-ISSN 2654-8003

\footnotetext{
\ Alamat korespondensi: rohmatullah170197@gmail.com

Universitas Singaperbangsa Karawang, Jl. HS.Ronggo Waluyo, Puseurjaya, Kec. Telukjambe Tim., Kabupaten

Karawang, Jawa Barat 41361, Indonesia
} 


\section{PENDAHULUAN}

Pendidikan jasmani adalah komponen terstruktur dari pelaksanaan pembelajaran keseluruhan dan memfokuskan suatu pelaksanaan dan hasil (Gani et al., 2019). Penjas adalah alat untuk mendukung kemajuan kapabilitas motorik, kesanggupan jasmani, pemahaman, logika, pendalaman nilai (perilaku, kejiwaan, emosionil, kerohanian, kemasyarakatan) dan membahas gaya hidup sehat yang bermanfaat untuk menstimulus pertumbuhan dan perkembangan yang berimbang. Melalui pendidikan jasmani siswa hendak mendapatkan bermacam pernyataan yang ideal erat hubungannya dengan jejak diri yang menggembirakan dan bermacam ungkapan yang kreatif, inovatif, terampil, mempunyai kesegaran jasmani, kultur hidup sehat serta mempunyai pengetahuan serta pemahaman kepada pergerakan manusia (Wibowo \& Gani, 2018).

Pendidikan jasmani ialah satu diantara cara untuk meningkatkan keterampilan belajar (Ngolo \& Ohoirat, 2018). Pada pelaksanaan pembelajaran pendidikan jasmani guru perlu mengajari beragam keterampilan gerakan dasar, teknik, taktik permainan dan karakter yang sportif, berprilaku terbuka dan mampu bekerjasama. Selain itu guru Penjas semestinya dapat menjadi guru profesional yang mempunyai kecakapan dan ahli dibidang keguruan sehingga sanggup menjalankan kewajiban dan perannya sebagai guru dengan kesanggupan optimal (Budiantara et al., 2014). Salah satu materi yang ada di Penjas adalah sepak bola

Permainan sepak bola adalah salah satu cabang olahraga yang dilakukan oleh kedua tim yang tiap-tiap tim memainkan berisi 11 pemain, dan umumnya satu tim diungkap juga dengan kesebelasan. Target kunci dari permainan sepak bola ialah tiap-tiap tim atau kesebelasan berupaya membuat bola masuk atau merebut gol maksimal ke gawang musuhnya dan membentengi gawangnya sendiri supaya tak kebobolan (Nosa \& Faruq, 2013). Sepak bola merupakan salah satu permainan yang dilaksanakan dengan metode menendang bola kesana kemari yang dijalankan oleh pemain, dengan target gawang serta bermaksud membuat masuk bola ke gawang musuh (Hamzah, 2019). Dari pernyataan tersebut dapat disimpulkan bahwa sepak bola ialah suatu permainan yang didalamnya terdiri dari dua tim dan 11 pemain tiap timnya yang bertujuan memasukan bola kepada 
musuhnya dan membentengi gawangnya agar bola tidak masuk ke gawang sendiri.

Dalam permainan sepak bola setiap pemain diharuskan mempunyai keterampilan teknik dasar yang baik serta diwajibkan bekerjasama dalam tim selama berlangsungnya permainan (Taufik et al., 2019). Keterampilan bermain sepak bola amat penting diatur oleh setiap pemain, sebab jika keterampilan dasarnya bagus maka perolehan hasil olahraga sepak bola akan gampang ditempuh (Nusufi, 2016). Pemain tidak semata-mata hanya memiliki jasmani serta kejiwaan yang kokoh, namun juga teknik dasar bermain yang terampil, termasuk dalam melakukan passing.

Passing merupakan salah satu diantara teknik dasar dalam bermain sepak bola yang dilaksanakan dengan metode menendang bola ke target yang sudah ditetapkan oleh seorang pemain, sebab keterampilan hal yang demikian (passing) menolong di dalam membangun serangan ke arah pertahanan musuh dan sekalian menghasilkan kesempatan-kesempatan untuk menciptakan gol. Passing merupakan cara mengoper atau dipindahkannya kesempatan bola dari tiap pemain ke pemain yang lain (Effendi, 2017). Passing merupakan memberi operan bola terhadap teman sendiri didalam sebuah tim dengan suatu cara eksklusif (Putra et al., 2014). Berdasarkan argumentasi tersebut dapat disimpulkan bahwa passing adalah teknik dalam sepak bola yang bertujuan mengoper bola kepada kawan sendiri. Keterampilan dasar sepak bola amatlah penting untuk mendukung keberhasilan sebuah tim dalam memenangkan pertandingan, terutama passing. Dengan menguasai keterampilan passing akan membantu tim dalam melakukan penyerangan dan akan menghasilkan banyak peluang untuk menjadi gol.

Passing tidak dilakukan dengan sembarangan, ada teknik pelaksanaan yang perlu diperhatikan oleh setiap pemain dari posisi bahu ataupun kaki. Jika teknik pelaksanaanya tidak diperhatikan dengan baik, dapat dipastikan passing yang dilakukan tidak sampai ataupun tidak mengarah kepada target. Oleh karena itu penting bagi setiap pemain untuk memperhatikan hal tersebut. Teknik dasar passing diterapkan untuk tipe operan datar yang operannya relatif kian pesat dibanding operan yang lain. Secara umum teknik pelaksanaan passing ialah berdiri dengan bahu mengarah target, tempatkanlah kaki penopang di sisi bola, 
tempatkan kaki ayun dengan jari-jari kaki menuju ke atas, selanjutnya tendang bola persis di tengah dengan memakai kaki komponen tepi ayun, berikutnya gerakan tendangan menghadap depan dengan konsisten memperhatikan letak kaki (Heri, 2017).

Pembelajaran sepak bola merupakan pembelajaran yang sangat ditunggutunggu terutama oleh siswa putra, namun keterbatasan yang terjadi adalah isi dalam materi tersebut yang terkadang sukar dikuasai oleh siswa. Pemenuhan pembelajaran sudah dilakukan oleh guru begitu juga dengan dikembangkannya metode dan model pembelajaran, namun kondisi tersebut masih belum teratasi. Berdasarkan kondisi yang ada terdapat beberapa penyebab masalah diantaranya kemampuan keterampilan siswa itu sendiri. Dengan hal demikian peneliti tertarik untuk melakukan sebuah penelitian yang terkait untuk mengetahui keterbatasan yang ada dalam kesanggupan psikomotorik dalam proses pembelajaran sepak bola. Adapun tujuan penelitian ini yaitu untuk melihat tingkat keterampilan siswa dalam melakukan passing pada pembelajaran sepak bola siswa kelas X di SMAN 1 Jasinga.

Penelitian ini juga sudah dilakukan oleh (Santoso, 2014) dengan judul penelitiannya "Tingkat Keterampilan Passing-Stoping dalam Permainan Sepak Bola pada Mahasiswa PJKR B Angkatan 2013" dengan data penelitian passing putranya adalah dengan kategori baik sebanyak 5 mahasiswa dengan persentase $18.52 \%$, kategori sedang sebanyak 17 mahasiswa dengan persentase $62.96 \%$, kategori kurang sebanyak 5 mahasiswa dengan persentase $18.52 \%$. Sedangkan mahasiswi putri dengan kategori baik sebanyak 3 mahasiswi dengan persentase $20 \%$, kategori sedang sebanyak 9 mahasiswi dengan persentase $60 \%$, dan kategori kurang sebanyak 3 mahasiswi dengan persentase 20\%. Secara penelitian sama mengukur tingkat keterampilan passing namun sampelnya berbeda peneliti mengukur keterampilan passing di tingkat SMA khususnya SMAN 1 Jasinga. Kebaruan penelitian ini adalah mengukur keterampilan passing sepak bola dengan tes yang berbeda dengan mengambil dari (Jaelani, 2014). Adapun tes passing dilakukan dengan mengarahkan ke teman di depannya sebagai pemantul untuk melakukan passing kembali sedangkan penelitian terdahulu melakukan tes passing dengan memantulkan ke papan. 


\section{METODE}

Penelitian ini menggunakan pendekatan deskriptif kuantitatif dengan metode survey. Populasi penelitian ini adalah siswa kelas X SMAN 1 Jasinga dengan jumlah 260 siswa. Adapun penarikan sampling menggunakan purposive sampling. Purposive sampling ialah teknik menetapkan sampel dengan penilaian terpilih (Sugiyono, 2017). Purposive sampling disebut juga dengan judgement sampling (sampling yang sudah ditentukan) dipilih secara terencana dengan memilih sampel yang mempunyai kualitas sesuai dengan kriteria peneliti (Etikan et al., 2016). Penelitian ini menggunakan kriteria : (1) siswa kelas X SMAN 1 Jasinga (2) Siswa laki-laki (3) siswa yang sudah bisa passing. Sehingga sampling yang digunakan berjumlah 30 orang siswa putra.

Instrumen penelitian yang digunakan untuk mengukur keterampilan passing ialah tes keterampilan passing yang dipergunakan dan sumbernya dari (Jaelani, 2014). Teknik pengumpulan data yang dipergunakan ialah tes keterampilan passing. Teknik dalam analisis data menggunakan deskriptif persentase menggunakan kriteria kelompok dengan kategori sangat baik, baik, cukup baik, kurang baik, dan sangat kurang (Aqib, 2011)

\section{HASIL DAN PEMBAHASAN}

Data hasil tes keterampilan passing pada pembelajaran sepak bola di SMAN 1 Jasinga diperoleh melalui survei dengan teknik tes. Tes yang digunakan adalah tes keterampilan passing dengan cara siswa melakukan passing kemudian siswa lainnya mengontrol bola tersebut dan selanjutnya mengembalikan bola dengan melakukan passing kembali. Distribusi penilaian keterampilan passing pada pembelajaran sepak bola siswa kelas X SMAN 1 Jasinga disajikan dalam tabel berikut: 
Tabel 1. Data Keterampilan Passing

\begin{tabular}{lcccc}
\hline No & Rentang Skor (\%) & Kategori & F & $\%$ \\
\hline 1 & $\geq 80$ & Sangat Baik & 6 & $20.0 \%$ \\
2 & $60-79$ & Baik & 16 & $53.3 \%$ \\
3 & $40-59$ & Cukup Baik & 8 & $26.7 \%$ \\
4 & $20-39$ & Kurang Baik & 0 & $0.0 \%$ \\
5 & $\geq 20$ & Sangat kurang & 0 & $0.0 \%$ \\
\hline
\end{tabular}

Tabel 1 menunjukkan bahwa keterampilan passing siswa kelas X SMAN 1 Jasinga yang berjumlah 30 orang, berada pada kategori sangat baik berjumlah 6 orang dengan persentase $20.0 \%$, pada kategori baik berjumlah 16 orang dengan persentase $53.3 \%$, pada kategori cukup baik berjumlah 8 orang dengan persentase $26.7 \%$ sedangkan pada kategori kurang baik dan sangat kurang tidak ada. Hasil dari penelitian tersebut bahwa tingkat keterampilan passing siswa kelas X SMAN 1 Jasinga berada pada kategori baik. Sedangkan penelitian sebelumnya yang dilakukan oleh (Santoso, 2014) dengan hasil tes keterampilan passing berada dalam kategori sedang.

Dengan kondisi keterampilan passing siswa kelas X SMAN 1 Jassinga dalam pembelajaran sepak bola yang berada pada kategori baik (16 orang atau sekitar 53.3\%) sudah bagus. Siswa sudah dapat mempraktikkan kemampuan geraknya dengan baik sehingga diharapkan dapat mencapai nilai yang baik juga saat pembelajaran. Walaupun demikian, guru harus tetap memperhatikan pengembangan metode dan model pembelajaran agar terciptanya tujuan pembelajaran sepak bola itu sendiri.

Teknik passing yang baik mesti diperhatikan oleh pemain sepak bola supaya bentuk permainan yang diharapkan dapat sukses entah itu disaat penyerangan ataupun dalam pertahanan. Pemain harus mampu mengendalikan bola selama permainan supaya bisa menjalankan beragam keterampilan dasar pada saat bermain (Syaifuddin et al., 2017). Passing yang terbaik dijalankan dengan menerapkan kaki, namun komponen tubuh lainnya juga dapat dipakai untuk menjalankan passing diantaranya dengan menerapkan kepala. Passing dilakukan dengan menerapkan kepala dijalankan dengan mengayunkan kepala kebelakang 
saat bola akan mendekat kemudian ayunkan kepala ke depan saat bola sudah berada pada posisi siap sundul. Passing memerlukan keterampilan teknik yang sangat baik supaya bisa konsisten menguasai bola. Melalui passing yang terbaik seorang pemain dapat berlari ke celah terbuka serta mengontrol permainan ketika menciptakan taktik permainan. Passing diawali saat tim yang sedang menguasai bola menghasilkan celah di sela-sela musuh dengan beranjak dan melahirkan celah di sekitaran pemain (Sudrajad, 2016).

Penguasaan kemampuan keterampilan passing siswa kelas X SMAN 1 Jasinga dikontrol dengan baik, itu ditunjukkan dengan hasil keterampilan passing siswa itu sendiri. Rata-rata siswa mengikuti aktivitas latihan yang ada di daerah masing-masing dan ada pula yang mengikuti ekstrakulikuler yang ada di sekolah. Pengendalian keterampilan itu bisa diterapkan ketika pelaksanaan pada saat materi sepak bola sehingga menjadi nilai plus bagi siswa itu sendiri. Dengan hal yang demikian tentu siswa mampu mendapatkan nilai yang bagus pula dalam aktivitas belajar mengajar.

Menurut (Saputra et al., 2016), pelaksanaan pembelajaran terutama materi bermain sepak bola untuk memaksimalkan interpretasi pasti terdapat penuh masalah yang umumnya dijalani oleh siswa, siswa ada kalanya tidak mutlak menerima pengetahuan yang maksimal dari kegiatan yang dikerjakan. Keadaan ini tidak diragukan lagi diberi pengaruh oleh sebagian unsur, entah itu internal ataupun eksternal dari siswa. Pelaksanaan pembelajaran juga tengah berfokus kepada guru, siswa senantiasa mencontoh pembelajaran dengan fungsi guru selaku teladannya. Selama pelaksanaan pembelajaran guru yang mengontrol semua aktivitas pembelajaran, dengan hal demikian fungsi siswa masih kurang, siswa sekedar mencontoh perintah guru, dan belum bisa memaksimalkan secara optimal kemauan gerak atau kerajinan mereka dalam pelaksanaan pembelajaran (Rusdi \& Julfiansyah, 2016).

Agar di dalam pembelajaran siswa sanggup mencontoh dengan baik dan fungsi dari pembelajaran dapat berhasil, karenanya pelaksanaan dalam pembelajaran pendidikan jasmani ialah seharusnya konsentrasi kepada siswa (student center) bukan kepada guru (teacher center) dengan demikian guru patut memperhatikan kemampuan siswanya (Gani et al., 2020). Dari pernyataan 
tersebut, siswa khususnya kelas X SMAN 1 Jasinga dituntut untuk lebih aktif lagi agar terciptanya pembelajaran yang tidak hanya berfokus pada guru sehingga fungsi pembelajaran pun bisa tercapai.

Mengajarkan cara passing dengan bagus, harusnya seorang guru pendidikan jasmani bisa membagikan rencana pendidikan yang menarik serta membuat suka siswanya dengan wujud permainan supaya keterampilan teknik dasar passing siswanya berkembang (Hutajulu, 2013). Seorang guru Penjas perlu memberikan program-program pembelajaran yang menarik agar siswa mau dan bersemangat mengikuti pembelajaran passing, sehingga keterampilan passing dapat berkembang dalam pembelajaran sepak bola.

Penelitian ini mendukung hasil penelitian yang pernah diteliti (Udyatama, 2017) dengan judul "Survey Keterampilan Passing, Shooting, dan Dribbling dalam Permainan Sepak Bola di SSB Siswa Tama U-12 Kediri” Adapun perbedaan penelitian ini yaitu peneliti tidak melakukan penelitian terhadap semua teknik dasar sepak bola, melainkan hanya teknik dasar passing nya saja. Selain itu penelitian ini juga mendukung oleh hasil penelitian (Sudrajad, 2016) dengan judul penelitiannya "Tingkat Kemampuan Ketepatan Passing Kaki Bagian Dalam Pada Siswa Peserta Ekstrakurikuler Sepak Bola di SMP Negeri 1 Imogiri Kabupaten Bantul Tahun 2016" perbedaan penelitiannya pada populasi dan sampel yang dipilih peneliti melakukan penelitian tingkatan SMA. Penelitian ini terdukung juga oleh penelitian yang diteliti oleh (Pratama, 2017) dengan judul penelitiannya “Tingkat Keterampilan Gerak Dasar Passing-Stopping Heading Dribbling dan Shooting dalam Permainan sepak bola pada Siswa SMA Negeri 1 Lendah yang Mengikuti Ekstrakurikuler sepak bola Tahun Ajaran 2016 / 2017" dengan hasil penelitiannya mengukur keterampilan teknik dasar sepak bola keseluruhan sedangkan peneliti mengukur keterampilan passing nya saja.

\section{SIMPULAN}

Keterampilan passing pada pembelajaran sepak bola siswa kelas X di SMAN 1 Jasinga berada pada kategori baik. Hasil ini bagus namun harus tetap ditingkatkan lagi keterampilan passing nya agar mendapatkan hasil yang lebih maksimal. Dari hasil penelitian ini dapat diketahui pentingnya melakukan 
kegiatan di luar pembelajaran seperti mengikuti ekstrakurikuler dan mengikuti latihan di daerah masing-masing sehingga penguasaan keterampilan passing bisa diterapkan saat pembelajaran sehingga siswa dapat memperoleh hasil nilai yang baik.

\section{DAFTAR RUJUKAN}

Aqib, Z. (2011). Penelitian tindakan kelas untuk guru SD, SLB dan TK. Bandung: CV. Yrama Widya.

Budiantara, I. K., Artanayasa, I. W., \& Satyawan, I. M. (2014). Implementasi model kooperatif tps untuk meningkatkan aktivitas dan hasil belajar passing sepakbola. Jurnal Pendidikan Jasmani, Olahraga Dan Kesehatan Undiksha, 2(1), 1-11.

Effendi, A. R. (2017). Meningkatkan keterampilan passing pada permainan sepak bola. Jurnal Pendidikan Olahraga, 6(2), 65-74.

Etikan, I., Musa, S. A., \& Alkassim, R. S. (2016). Comparison of convenience sampling and purposive sampling. American Journal of Theoretical and Applied Statistics, 5(1), 1-4.

Gani, R. A., Sukur, A., \& Nugroho, S. (2019). Peningkatan kemampuan renang gaya kupu-kupu. Jurnal Pendidikan Jasmani Dan Olahraga, 18(2), 107113.

Gani, R. A., Winarno, M. E., Aminudin, R., Dimyati, A., \& Bayu, D. (2020). Gaya mengajar resiprokal untuk peningkatan teknik grab start. Jurnal Keolahragaan, 8(1), 98-107.

Hamzah, A. G. (2019). Penerapan model pembelajaran gaya reciprocal untuk meningkatkan teknik passing pada permainan sepak bola siswa SMA Negeri 14 Makassar. Fakultas Ilmu Keolahragaan Universitas Negeri Makassar, 1(1), 1-10.

Heri, R. (2017). Upaya meningkatkan keterampilan passing sepakbola dengan kaki bagian dalam menggunakan metode bermain. Jurnal Pendidikan Olahraga, 6(1), 21-32.

Hutajulu, P. T. (2013). Meningkatkan keterampilan teknik dasar passing sepakbola melalui pengembangan model belajar permainan pada siswa putra kelas v SD. Jurnal Pendidikan Jasmani Olahraga Dan Kesehatan, 1(1), 4651.

Jaelani, R. (2014). Penerapan metode drill dalam meningkatkan kemampuan teknik menendang dengan kaki bagian dalam pada permainan sepak bola siswa kelas viii MTS Sukajaya Cilamaya Kulon Karawang. Tidak diterbitkan. Karawang. Universitas Singaperbangsa Karawang. 
Ngolo, H., \& Ohoirat, M. N. A. G. (2018). Pengembangan model pembelajaran passing permainan sepak bola di SMP Negeri 7 Wasilei Halmahera Timur. Jp. Jok (Jurnal Pendidikan Jasmani, Olahraga Dan Kesehatan), 2(1), 3041.

Nosa, A. S., \& Faruq, M. (2013). Survei tingkat kebugaran jasmani pada pemain persatuan sepakbola Indonesia Lumajang. Jurnal Prestasi Olahraga, 1(1), $1-8$.

Nusufi, M. (2016). Hubungan kemampuan motor ability dengan keterampilan bermain sepak bola pada klub Himadirga Unsyiah. Jurnal Pedagogik Keolahragaan, 02(01), 1-10.

Pratama, A. Y. (2017). Tingkat keterampilan gerak dasar passing-stopping heading dribbling dan shooting dalam permainan sepakbola pada siswa SMA Negeri 1 Lendah yang mengikuti ekstrakulikuler sepakbola tahun ajaran 2016 / 2017. Journal Student, 6(1), 1-9.

Putra, I. komang A., Kanca, I. N., \& Wijaya, I. M. K. (2014). Implementasi pembelajaran kooperatif nht untuk meningkatkan aktivitas dan hasil belajar teknik dasar passing sepak bola. Jurnal Pendidikan Jasmani, Olahraga Dan Kesehatan Undiksha, 2(1), 1-11.

Rusdi, \& Julfiansyah, U. (2016). Meningkatkan hasil belajar passing kaki bagian dalam permainan sepak bola dengan metode bermain pada siswa kelas xi pemasaran SMK Negeri 1 Sambas Kabupaten Sambas. Jurnal Pendidikan, 14(1), 122-131.

Santoso, N. (2014). Tingkat keterampilan passing-stoping dalam permainan sepakbola pada mahasiswa PJKR B angkatan 2013. Jurnal Pendidikan Jasmani Indonesia, 10(2), 40-48.

Saputra, G., Kaswari, \& Atiq, A. (2016). Survei keterampilan teknik dasar sepak bola di kelas xi SMAN 1 Mempawah Hilir. Program Studi Pendidikan Jasmani Dan Rekreasi FKIP UNTAN, 1(1), 1-12.

Sudrajad, A. (2016). Tingkat kemampuan ketepatan passing kaki bagian dalam pada siswa peserta ekstrakulikuler sepak bola di SMP Negeri 1 Imogiri Kabupaten Bantul tahun 2016. Prodi Pendidikan Jasmani Kesehatan Dan Rekreasi Jurusan Pendidikan Olahraga Fakultas Ilmu Keolahragaan Universitas Negeri Yogyakarta, 6(1), i-59.

Sugiyono. (2017). Metode penelitian pendidikan: pendekatan kuantitatif, kualitatif, $r \& d$. Bandung: CV Alfabeta.

Syaifuddin, M. F., Hariyoko, \& Wahyudi, U. (2017). Pengaruh metode drill dan metode bermain terhadap hasil belajar passing sepakbola pada peserta ekstrakulikuler sepakbola usia 16-17 tahun. Jurnal Gelanggang Pendidikan Jasmani Indonesia, 1(2), 271-281.

Taufik, M. S., \& Gaos, M. G. (2019). Peningkatan hasil belajar dribbling sepak 
bola dengan menggunakan media audio visual. Jp. Jok (Jurnal Pendidikan Jasmani, Olahraga Dan Kesehatan), 3(1), 43-54.

Udyatama, L. F. (2017). Survei keterampilan passing, shooting, dan dribbling dalam permainan sepak bola di ssb siswa Tama u-12 Kediri. Program Studi Penjaskesrek Fakultas Keguruan Dan Ilmu Pendidikan Universitas Nusantara PGRI Kediri, 1(1), 1-8.

Wibowo, H., \& Gani, R. A. (2018). Pendidikan jasmani materi ajar passing bawah dalam permainan bola voli pada siswa kelas vii SMP Negeri 2 Majalaya. Jurnal Speed, 1(1), 45-50. https://doi.org/http://dx.doi.org/10.35706/speed.v1i1.1497 